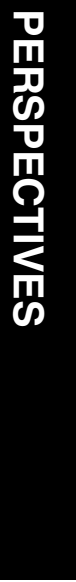

Department of

Ophthalmology,

Birmingham and Midland Eye Center, City Hospital NHS Trust, Birmingham, UK

Correspondence: P Shah, Ophthalmology,

Birmingham and Midland Eye Center,

City Hospital NHS Trust,

Dudley Road,

Birmingham B18 7QU, UK

Tel: +44121507 6800;

Fax: + 441215076791

E-mail: p.f.shah@

talk21.com

Received: 14 April 2005

Accepted in revised form:

26 August 2005

Published online: 27 January

2006

PS and VC devised the Shah-Cross Model. VC designed and carried out the qualitative research study, and was involved at every stage of preparation and presentation of this paper. PS conceived and is leader of the Birmingham ReGAE Project. PS is the guarantor.

The following organizations

funded the research:

Birmingham Strategic

Health Authority,

Heart of Birmingham

Teaching Primary Care Trust,

City Hospital NHS Trust,

Pfizer, UK

Birmingham Social Services

\section{ReGAE 1: using the Shah-Cross model as an orientating framework in African-Caribbean glaucoma research}

\begin{abstract}
The inter-relationship between health-care research, policy and service development is convoluted and difficult to articulate. This paper describes a framework for planning research into a range of ophthalmic conditions differentially associated with specific ethnic groups. It discusses the utility of the 'ShahCross Model' in mapping development of a glaucoma research project, and communicating its implications for local eye-care policy and ophthalmic services directed towards detection and management of primary open-angle glaucoma in the African-Caribbean population in the UK. Eye (2006) 20, 988-997. doi:10.1038/sj.eye.6702130; published online 27 January 2006
\end{abstract}

Keywords: glaucoma; ethnicity; AfricanCaribbean; blindness

\section{Introduction}

Important priorities in health-care policy involve confronting ethnic disparities in uptake and provision and ensuring effective access for black and minority ethnic groups (BME) to services that are culturally sensitive and competent. ${ }^{1,2}$ It is also acknowledged that specific disease burdens are sufficiently great in some ethnic groups to justify increased attention from researchers, health professionals, and policy makers. The problem of glaucoma in the African-Caribbean population is an example of one such disease burden. ${ }^{3}$ Other key policies include reorienting service provision around users, and coordinating care across conditions, providers and settings. ${ }^{4,5}$
P Shah and V Cross

The Shah-Cross model

Inevitably, research that addresses such inter-related issues has a diverse audience of stakeholders interested in its process and outcomes. However, the tension between making research findings accessible and comprehensible without losing the complexity, poses a challenge to communication. ${ }^{6}$ Enabling researchers, policy makers, service providers and users to stay orientated to the research process and develop their thinking around emergent findings can present a dilemma. In this paper we describe how, as part of a multidisciplinary team researching into AfricanCaribbean glaucoma, we devised an orientating framework - the Shah-Cross model-for sharing our perceptions, defining objectives and planning research activities within the research team, and communicating our findings to other stakeholders. A key value of the Shah-Cross model lies in providing a graphic representation or map, on which to draw links between emergent research findings and their implications for eye-care policy and service development. In this respect it has proved a dynamic tool in dissemination. To illustrate the model's evolution and potential application, we present some initial findings from the Birmingham Research into Glaucoma and Ethnicity (ReGAE) Project, a collaborative, multiphase programme of research aimed at reducing the risk of preventable glaucoma blindness and visual impairment in AfricanCaribbeans living in Birmingham UK.

\section{Key elements of the model}

To help visualise the inter-relationships between research objectives, activities and outcomes we 
drew three maps representing research (Figure 1a), policy (Figure 1b), and service development (Figure 1c). These make up the basic elements of the Shah-Cross model. In relation to each we conceptualise three overlapping territories making up the terrain. The peripheral areas of overlap in each map indicate foci for specific activity, while the central areas represent ethnically sensitive practice in terms of research, policy making and service development, respectively. Below, we relate AfricanCaribbean glaucoma to the research map (Figure 1a). We then go on to consider some preliminary research findings in terms of the policy and service development maps (Figure $1 \mathrm{~b}$ and $\mathrm{c}$ ), to illustrate the model's value in facilitating communication and interaction between relevant stakeholders.

\section{Using the model to structure the ReGAE Project}

We began by customising the research map to reflect the context of the ReGAE Project. The territories making up the research terrain for African-Caribbean glaucoma were identified as eye-care service provision, primary openangle glaucoma (POAG) pathogenesis, and the relationship of ethnicity to these two factors. These defined the rationales for specific objectives and research activities associated with areas of overlap between these territories.

\section{Ethnicity and eye-care services (Figure 2)}

The glaucomas are a group of eye diseases with a characteristic, intraocular pressure dependent,

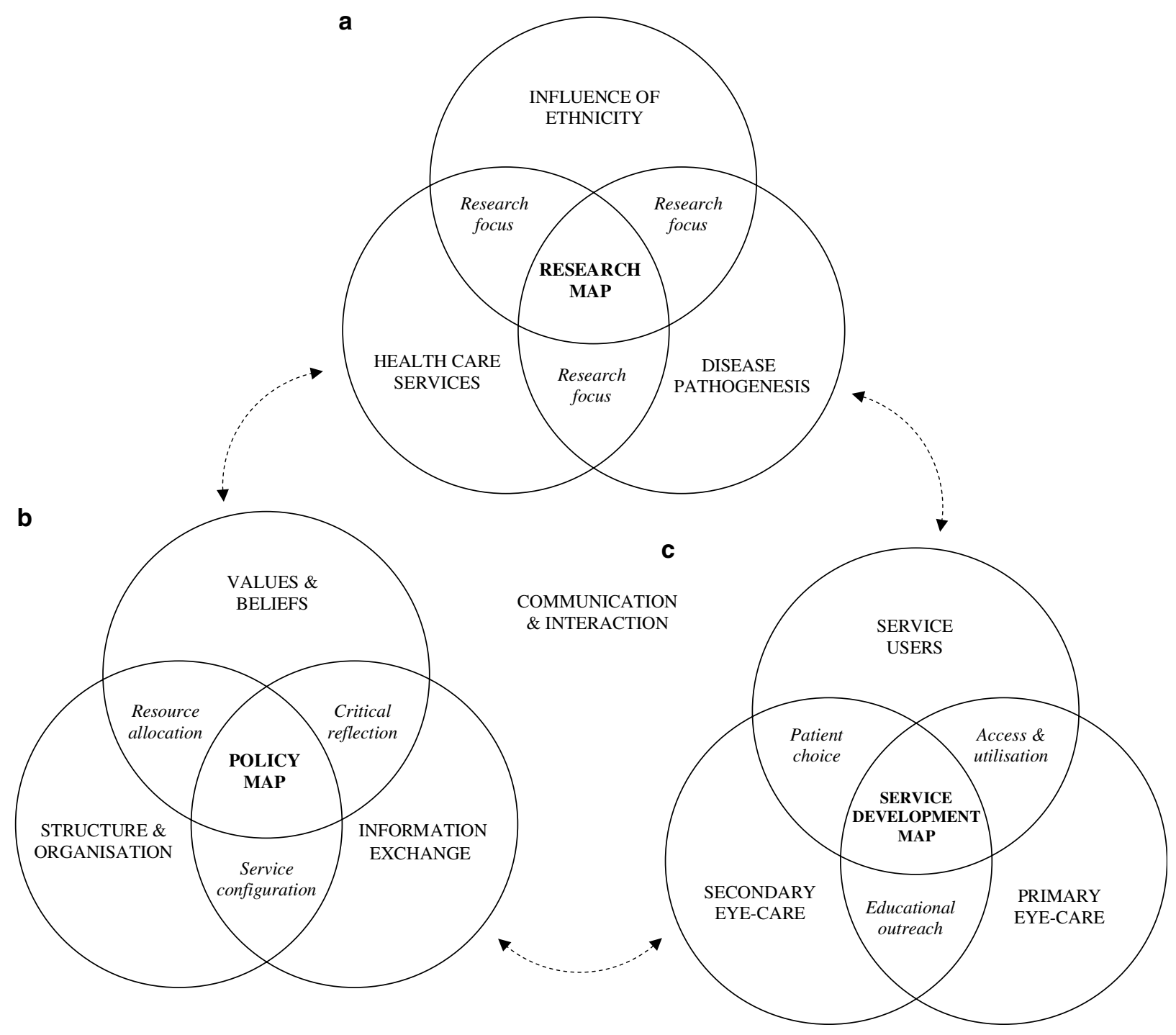

Figure 1 Key elements of the Shah-Cross model. 


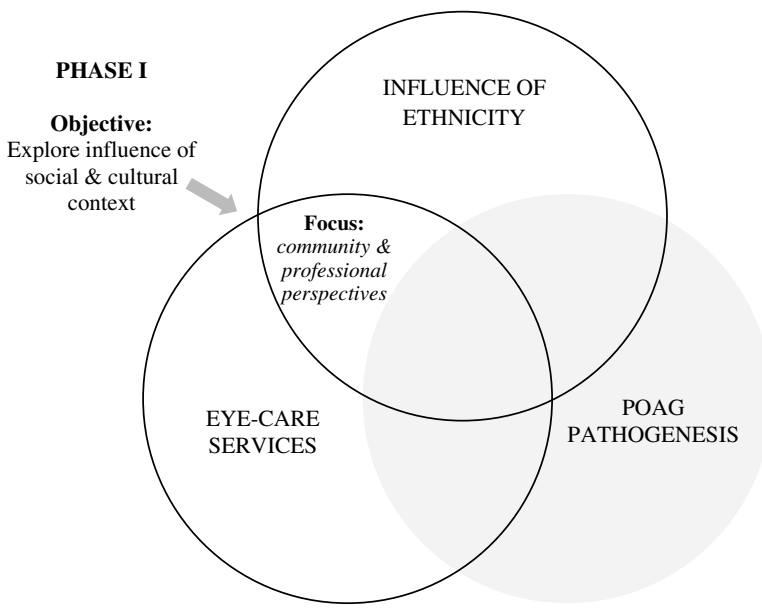

Figure 2 Research focus associated with ethnicity and eye-care services.

progressive optic neuropathy, which leads to irreversible visual loss. Adult onset POAG is a major cause of visual impairment and avoidable blindness in black people. Patients with established optic nerve disease at the start of treatment are significantly more likely to become blind. ${ }^{7}$ Despite this, glaucoma in African-Caribbeans remains underdetected and they continue to present late to the HES with advanced and irremediable optic disc damage..$^{7-9}$ Ethnic origin accounts for some, but not all of an association between socioeconomic status and late presentation and a strong association has been reported between African-Caribbean origin and late presentation. ${ }^{10,11}$ Given that glaucoma blindness is avoidable with early detection and treatment, investigating the overlap between ethnicity, access, and utilisation of eye-care services is a key focus of research activity to prevent unnecessary numbers of black people continuing to become blind as a result of POAG.

\section{POAG pathogenesis and ethnicity (Figure 3)}

People of African-Caribbean descent have been shown to be up to eight times more likely to develop POAG compared to people in other ethnic groups. The disease appears 10-15 years earlier than in people of other ethnic origin and family history is an important risk factor. ${ }^{12-17}$ Clinical observations of ethnic differences in POAG were first recorded over 60 years ago. However, there are still no clear answers as to why black people experience a disproportionate burden of glaucoma blindness and visual impairment. ${ }^{16}$ In people of all ethnicities, the early to middle phase of POAG is usually asymptomatic. Loss of visual field does not appear until the disease is well established, by which time $30-50 \%$ of the optic nerve

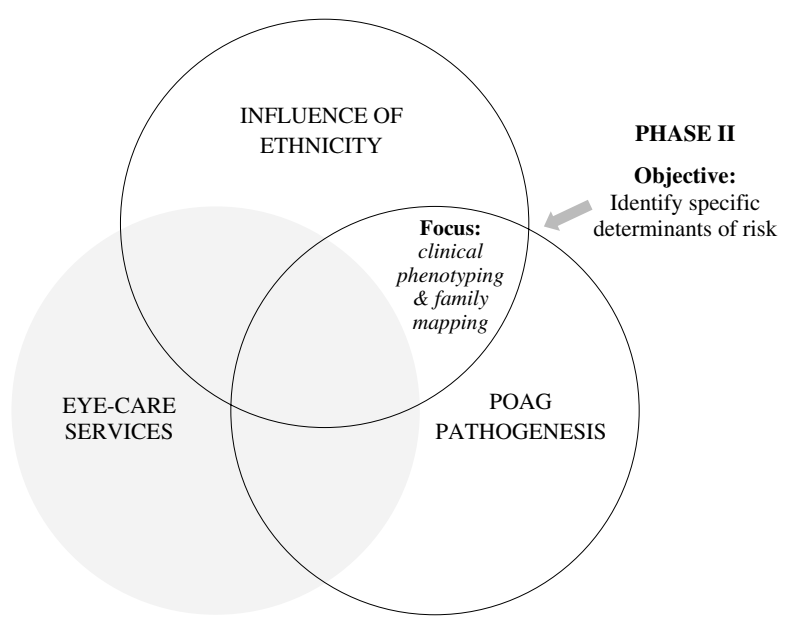

Figure 3 Research focus associated with ethnicity and POAG pathogenesis.

may have been irrevocably damaged. ${ }^{18}$ Early case detection is crucial to preventing blindness, however, standard methods for detection tend to generate a high number of false positives. The overlap between POAG pathogenesis and ethnicity represents the fact that in the African-Caribbean eye early detection is particularly problematic, because its phenotypical parameters (the anatomical or structural components of the eye involved in POAG pathogenesis) have yet to be clearly defined. Thus, family mapping of POAG in the local community accompanied by research into clinical phenotyping and genotyping are important research foci. An additional problem in the management of African-Caribbean glaucoma is that the disease process itself is often more aggressive, and can be more refractory to medical and surgical therapy when compared to glaucoma in white populations. ${ }^{7}$ Analysis of the clinical effectiveness of glaucoma interventions is an important part of the ReGAE Project.

\section{POAG pathogenesis and eye-care services (Figure 4)}

In the UK approximately $80 \%$ of referrals to the hospital eye service (HES) originate from routine sight tests by optometrists in the primary eye-care service (PECS). Yet, only about $33 \%$ of routine suspect glaucoma referrals to the HES are subsequently found to have glaucoma. ${ }^{19}$ Difficulties with optic disc assessment are implicated in the high percentage of false positives. ${ }^{20}$ Clear definition of the normal range of phenotype for the AfricanCaribbean eye would help reduce this and facilitate early detection. Additional training in optic disc assessment and glaucoma management could assist in reducing HES referrals and freeing up ophthalmologist time..$^{21,22}$ Therefore, investigating case finding and referral 
patterns, as well as scoping the knowledge and skill development needs among local community optometrists are necessary research activities.

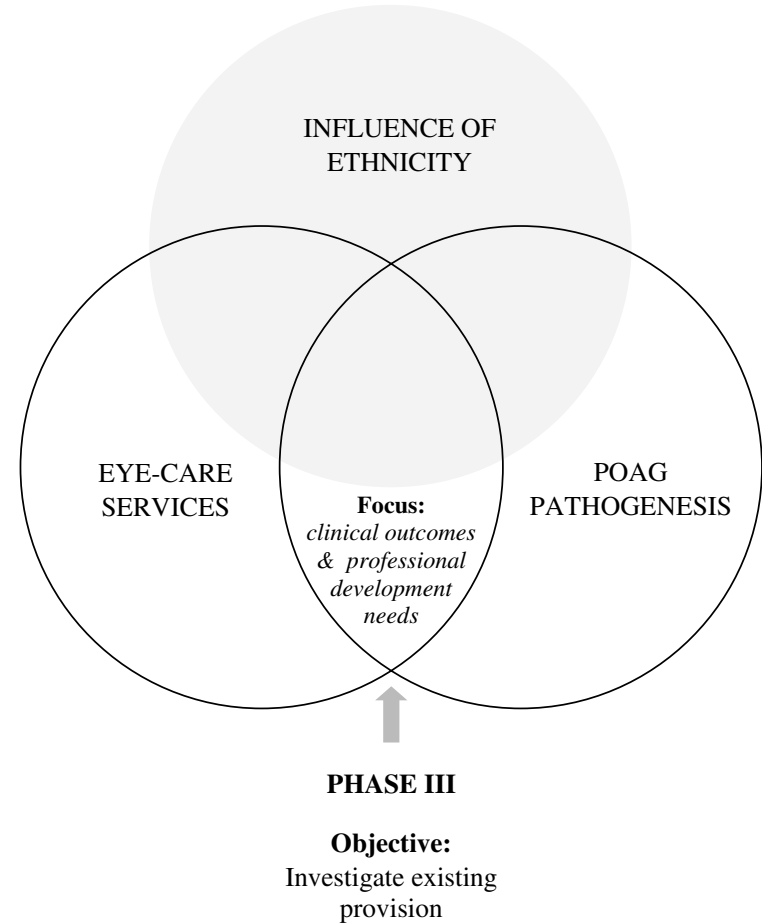

Figure 4 Research focus associated with eye-care services and POAG pathogenesis.

\section{Sequencing research activities (Figure 5)}

Although the research territories described could be investigated simultaneously, in fact they have a sequential dimension, influenced by the patient-centred policy agenda. This defines a new role for patients and public in planning, developing, and evaluating health-care services and related research. Transition to this new role requires a different way of thinking and behaving on both sides. ${ }^{23}$ However, as with any step into unfamiliar territory, 'without a reasonably well-established sense of basic trust, it is difficult to move ahead'. ${ }^{24}$ What Bhopal $(1997)^{25}$ describes as 'the 'inglorious history' of racialised research' has been fundamental to concern about the need to build trust in the research process within BME communities, and engage in ethnically sensitive research, policy making and service development. Khaliq et al $(2003)^{26}$ identify four barriers to participation in research: mistrust of researchers, limited knowledge of health studies, limited community involvement in study design, and use of intrusive procedures.

Local ethnic identities and social networks appear to produce qualitatively different responses to recruitment in different communities. For this reason McLean and Campbell (2003) ${ }^{27}$ recommend formative research in a target community before commencing recruitment to a project. Given the disproportionate burden of glaucoma in black people, investigating

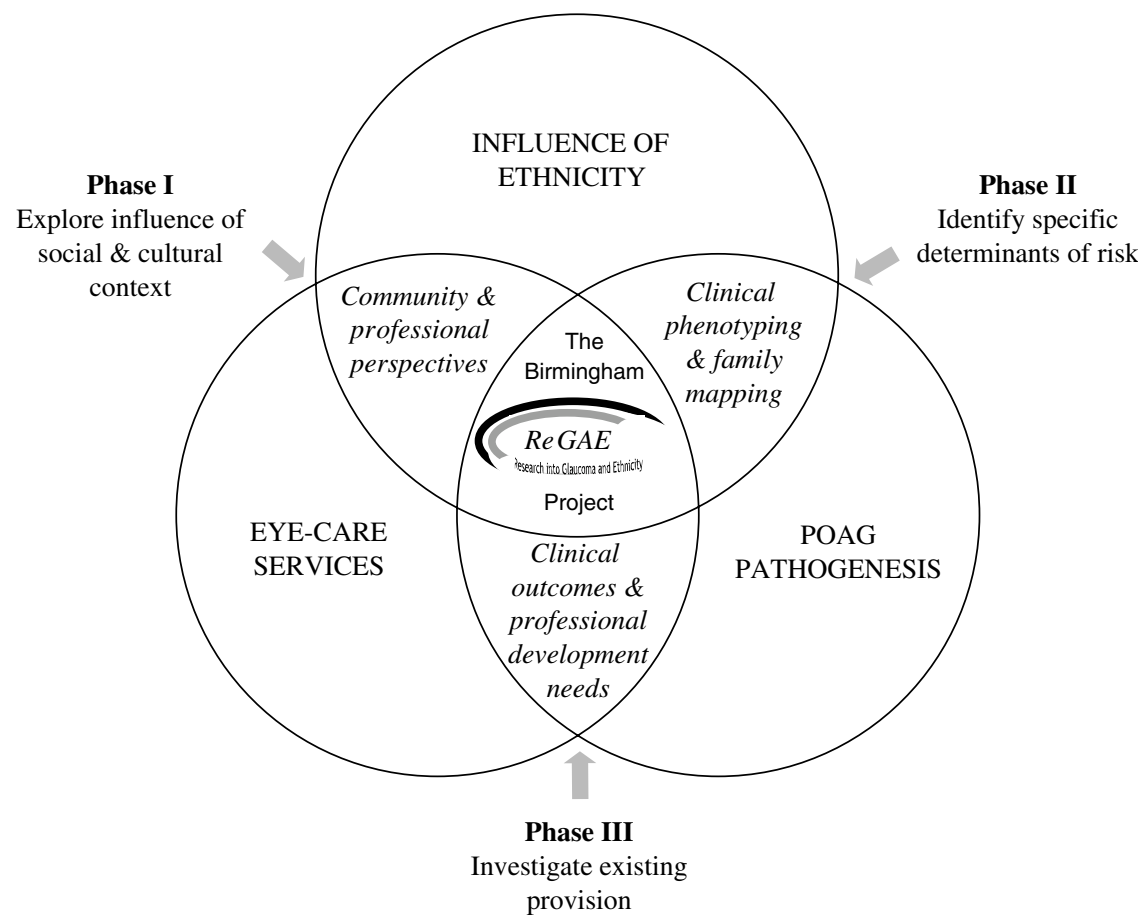

Figure 5 Map of the research terrain showing objectives and focus of research activities. 
the overlap between ethnicity and local eye-care services was indicated as the starting point of our research for two reasons. Firstly, it could facilitate involvement of the local community in the clinical aspect of the ReGAE Project (family mapping of glaucoma and phenotyping of the African-Caribbean eye by a research optometrist - an intrusive procedure). Secondly, the issues raised by the participants would inform subsequent attempts to scope the development needs of relevant eye-care professionals.
Linking ethnically sensitive research, policy and service development: examples from the interview study

....while our increasingly sophisticated technology can facilitate diagnosis, patient and community benefit does not follow if no assessment occurs. To encourage regular review, the community needs to know about glaucoma and the benefits of early detection. Without awareness, this seems unlikely. ${ }^{28}$

Box 1 Summary of phase I interview study

Glaucoma Awareness and the Primary Eye-Care Service:

Perceptions of a sample of African-Caribbeans in Birmingham ${ }^{30}$

Aims of the study:

- Investigate the extent of glaucoma awareness among African-Caribbean people in Birmingham.

- Elicit their responses to information about glaucoma risk.

- Identify influences and constraints on people's use of primary eye care services (PECS).

- Examine how far these responses might be influenced by aspects of individuals' health behaviour and their health care experiences.

- Inform development of an ethnically sensitive approach to glaucoma related health education and eye care service delivery.

Method:

A purposive convenience sample of 48 members of the local African-Caribbean community participated in the study ( 24 female, 24 male). The age range was 60 years (mean $=48$, median $=42$, interquartile range $=35$ ). One-to-one audio-taped interviews took place with 28 of the participants. Two focus groups were also conducted and audio-taped to gain specific perspectives on issues emerging from individual interviews. Focus Group 1 elicited an all male perspective from 6 men between the ages $34-43$ years, Focus Group 2 was made up of 13 members of a local diabetic support group.

Key prompts of interviews and focus groups:

- Can we start by talking a bit about your general approach to health issues, for example do you consider yourself a health person? (Probe: what are signs of good health, how is it maintained?)

- If you have a problem associated with your eyes where do you go for advice or help?

- What sorts of problems might take you to the optician?

- How would you describe your experiences at the optician? (Probe: what type of optician, tests, information given?)

- What are your feelings about having regular eye tests? (Probe: awareness of charges, exemptions)

- Did you know anything about glaucoma before taking part in this interview?

- Could you explain how you came by this information? (Probe: family history)

- What are your feelings about the risk of developing glaucoma, for example would you ever consider that you might develop the condition yourself? (Probe: reasons)

- What do you think would be some effective ways to help people find out about glaucoma and encourage them to go for an eye test? (Probe: impact on younger people, community resources)

- Is there anything else you would like to ask me about glaucoma?

- Would you mind telling me how you felt about the interview?

Additional prompts for focus groups:

- Some people (interviewees) have suggested that African-Caribbeans can be reluctant to discuss blindness in the family, is that your experience? (Probe: importance of family history of glaucoma)

- It seems less common to see black people who are blind or visually impaired using mobility aids such as guide dogs or long canes to go about their daily business, do you think that's so? (Probe: help-seeking, community support)

- Have you ever thought about what it must be like to be blind or visually impaired; what effects does it have on people's lives? (Probe: mechanism of glaucoma blindness)

Criterion for data saturation:

Sampling and integration of further data was considered complete when no new insights relating to agreed codes and categories were forthcoming. 
Box 2 Examples of perceptions of the primary eye-care service arising from the study

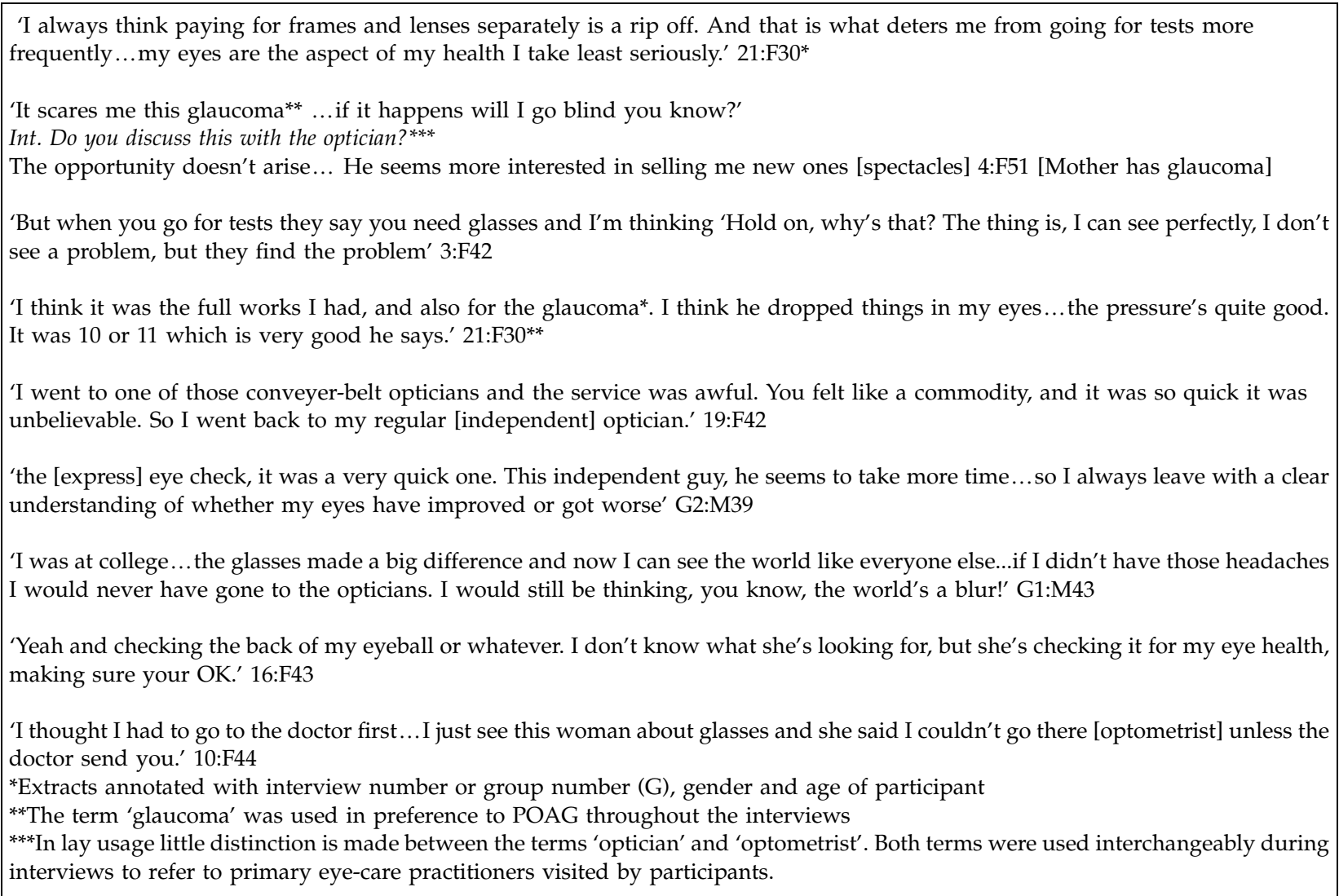

Box 3 Examples of participants' comments on glaucoma awareness and response to risk

'I used to think that you just go blind ... it just shut off, you just went blind. I never knew that you began to get the problem.' G2:M61*

'They don't understand it [glaucoma] ${ }^{* *}$ themselves. It's sort of like a taboo subject really, isn't it, illness? They really don't talk about it...you just say 'I've got...' end of story.' 15:M38

....my father was diagnosed with the glaucoma... The ins and outs of glaucoma I don't know, but I know it's to do with your eyes. But that is the only thing....you need to wear glasses, that's the long and short of it as far as I know. G1:M41

'We look at it as if we're gonna get it when we're older. We look at is as (grandmother) has that because she's old.' 26:F36

'... their reaction is something like, 'isn't that something that old people get, nah!' ... a lot of the people that I relate to at the gym... obviously a lot of them are Black, but they just looked upon it, 'No, no, that's for old people'.' 27:M45

No. there's no history of it in my family....I wouldn't say no-one a hundred per cent, but unlikely, 'cos I can't see why. I don't think I'd even ask at the opticians*** to be honest with you, 'cos I'd never have associated it with myself.' 21:F30.

*Extracts annotated with interview number or group number $(\mathrm{G})$, gender and age of participant.

**The term 'glaucoma' was used in preference to POAG throughout the interviews

*** In lay usage little distinction is made between the terms 'optician' and 'optometrist'. Both terms were used interchangeably during interviews to refer to primary eye-care practitioners visited by participants.

Investigations into glaucoma awareness have drawn predominantly on informed, clinic-based populations of mainly white ethnicities. There is a need to explore perceptions of those at risk, and potentially less informed, outside the HES. ${ }^{29}$ In particular, there is a need for differential exploration involving those at greater risk of avoidable blindness at an early age. Therefore, we began Phase I of our research with a qualitative interview study involving African-Caribbean participants outside the HES. Since community optometrists are currently the key professionals associated with glaucoma detection, we focused not only on the extent of glaucoma awareness 
Box 4 Examples of participants' responses to the interview and ideas for increasing glaucoma awareness

'... it got me to think a vast amount about my eyes and how little, in comparison to all the things that are issues for me...I don't think of my eyes as part of my health.' $21: \mathrm{F} 30^{*}$

'I think from my personal point of view, looking at our population being Black and all the rest of it, I think it'd have to be serious. 'Cos Black people are just the types of people from my own personal experiences, if it ain't serious, if it doesn't look serious it can wait till next week, next month, whatever. If it looks serious they'll be like 'Wow!' Not that we want to make anyone panic, but they need to know that it's serious to draw them. If not...' G1:M34

'I think for someone like myself, people who wear glasses ... I'm used to getting my eyes checked and this is something I'll be asking about, whereas before I'd just walk in and they'd do their thing. I'll talk to them about it. So it's important for me to know about my own health and safety.' G1:M43

'You need a lot more information in the doctors where people of colour go...I walk into my doctor's and don't see any information that says to me 'African-Caribbean people are suffering from glaucoma** quite a lot'.' G2:M61

'I think you've got communities, particularly in the Black church settings, and whatever message is in terms of ill health or education, you've got a ready audience.' G1:M43

'I intend, from what I've learnt, to take this on... because really it's all about the community coming together and it's all about educating as well. So we need to tap into different resources as well.' G2:F37

*Extracts annotated with interview number or group number $(G)$, gender and age of participant.

**The term 'glaucoma' was used in preference to POAG throughout the interviews

among our participants, but also on issues affecting their utilisation of PECS. The study is reported in full elsewhere. ${ }^{30}$ For the purposes of this paper the aims and method are summarised in Box 1 and relevant examples of participants' responses are presented in Boxes 2-4. In the following sections we explain how we used the Shah-Cross model as an orientating framework in discussing issues raised by the study with stakeholders. We made use of the model to link key elements of local eye-care policy (Figure 1b) and service development (Figure 1c) to the research findings. These elements of policy and service development are identified in italics in the following discussion.

\section{Mapping interview findings onto the policy terrain}

As Figure $1 \mathrm{~b}$ illustrates, three territories make up the policy terrain. Generic policy changes such as user involvement in planning and implementation of services, as well as specific changes, such as shared glaucoma care, challenge professionals' and service users' existing values and beliefs. At the same time they make new demands on communication and exchange of information. Overlap between these two policy territories marks out a crucial area for critical reflection on practice in relation to

- user- and provider-based cultural preferences, attitudes and norms;

- user and provider acceptance of change.

The interview study focused on user-based perceptions, and these provide a stimulus for critical reflection on policy-related issues. In relation to PECS utilisation

(Box 2) they indicate that among our participants

- although the clearest understanding of glaucoma was acquired from optometrists, quality and extent of information is inconsistent across modes of delivery;

- communication and credibility within PECS may be undermined by a perceived conflict of interest between commercial and diagnostic functions.

The extent of trust in PECS, and quality of communication, are factors that impact upon attempts to improve POAG case detection among AfricanCaribbeans. Dimensions of trust include, fidelity, honesty, and competence. ${ }^{31}$ Insofar as the competence dimension of trust refers to communication skills that enhance technical aspects of care, participants made qualitative distinctions between modes of delivery. Younger participants preferred the speedy and 'hasslefree' experience of some express delivery establishments. Older participants preferred independent practitioners or high street chains that offered a more thorough examination and more detailed information, even though this involved a protracted process of waiting and appointments. Acceptance of service reconfiguration in the form of shared/transferred glaucoma care by patients also depends upon belief in the trustworthiness and competence of PECS. If factors associated with structure and organisation of PECS are contributing to mistrust and misapprehension in some people, this could mean that inequities will remain despite service reconfiguration; that 'potential access' will not translate effectively into 
'realised access'. ${ }^{2}$ Dissociation of optometrists' role in glaucoma case detection from their commercial role could help avoid this. Structuring critical reflection on these issues by triangulating these PECS user perceptions with those of professional practitioners and HES users will help establish the validity of these initial findings. However, ultimately the overlap between structure and organisation and values (Figure 1b) may dictate what changes are realisable in terms of resource allocation that reflects

- commitment by funding bodies to financial investment in equipment and training for community optometrists in detection and management of POAG (particularly in young African-Caribbeans);

- capacity and willingness within the primary and hospital eye-care services to invest time and energy in the necessary professional development process.

Phases II and III of the ReGAE Project will help to inform these decisions.

\section{Mapping interview findings onto the service development terrain}

Service development (Figure 1c) grounds research outcomes and policy decisions in the realities of everyday practice. Hence, the territories of service delivery are represented by its key players; service users, primary eye-care practitioners, and secondary eye-care practitioners, whose interaction is fundamental to POAG detection, timely referral to the HES, and effective disease management.

Some supply-side quality issues identified in the study have been discussed above, and these have implications for access in the overlap between service users and PECS (Figure 1c). The interviews also revealed demand-side issues related to glaucoma awareness and response to risk, which influenced utilisation (Box 3). For example, glaucoma as a 'blinding condition of elderly people' (rather than an initially asymptomatic, potentially blinding condition of 30-50-year-old African-Caribbeans) led to an optimistic bias about the likelihood of developing POAG. Similarly, assumed lack of family history led to optimism in response to risk information. Participants' perceived invulnerability to POAG risk was, to some extent, compounded by their images of blindness, which did not fit with the clinical profile of POAG. Eye health was not integral to participants' schema of preventive health behaviour. Optometric visits were symptom driven, sometimes after an illness visit to the GP or secondary to other diagnoses such as diabetes. Normalisation of impaired visual acuity, by disguising or minimising symptoms suggests that PECS utilisation rates may not reflect actual level of need, and that any assumption that myopes are better informed about glaucoma through contact with PECS could be misguided.

That POAG is asymptomatic in its early to middle stages, coupled with the fact that a number of risk factors are inherited in families, accentuates the important role of family networks in promoting eye health and preventing blindness. ${ }^{32}$ Participants' reorientated their thinking about glaucoma, and the community's role in enhancing glaucoma awareness and education, as a consequence of taking part in the interview (Box 4). Their responses indicated focal points of intervention within the local African-Caribbean community upon which glaucoma-related health education could be tailored. ${ }^{33}$

\section{The interview study and further research}

The findings suggest there is a need for more information about POAG and glaucoma risk to be directed at AfricanCaribbean people living in Birmingham. Information needs to be disseminated as part of a reciprocal process that facilitates communication between eye-care professionals, the community and local health-care policy makers. Without this community agency in defining eye health, understanding POAG, and making choices about treatment and management will be constrained. It is clear that the supply and demand factors outlined above influence participants' motivation and level of self-efficacy in utilising PECS. Triangulating the findings of this early study with those of eye-care professionals and glaucoma patients in the local HES (the face and voice of glaucoma in the community) will contribute to informing patient choice as well as dialogue and debate about service reconfiguration involving shared/transferred care for glaucoma patients. As importantly, this early study has served a valuable formative function by preparing fertile ground for community involvement in research on clinical phenotyping of the African-Caribbean eye, which is an essential prerequisite for implementing appropriate educational outreach among eye-care professionals, enhancing glaucoma detection and reducing blindness rates in the African-Caribbean community.

\section{Conclusion}

People's use of health services is influenced by a range of psychological, social, cultural and practical factors. Eye-care services are no exception. ${ }^{32}$

It is important that a small local qualitative study, such as we have described here, does not attempt to generalise about African-Caribbeans by suggesting that 
they may have a particular response to glaucoma risk, or attitude towards PECS. Doing so would ignore the extent of heterogeneity within any ethnic community and the fact that attitudes and beliefs are unstable properties that may vary with time and context. ${ }^{34,35}$ What the study does do is help illuminate how eye-health behaviour is shaped by individuals' experiences and viewpoints, and the implications of this for glaucoma education and detection in a community differentially at risk of POAG. This paper used elements of the study to illustrate the value of an easily accessible map or framework - the 'Shah-Cross model'. The model was devised as a tool to clarify understanding of the underlying values and paradigms espoused by the research team, and enable relevant stakeholders stay orientated to emerging evidence from the complex glaucoma research project of which this study is an early part. It identifies clear reference points for further planning and research activity and acknowledges the centrality of local context by modelling a ground-up approach to ethnically sensitive eye-care research, policy making and service development. It is a starting point for continued evolution, rather than a refined model, but is transferable and could have value in facilitating interaction and dialogue related to a range of conditions differentially associated with specific ethnic groups.

\section{Acknowledgements}

We thank the individuals and organisations who gave up their time to facilitate and participate in the qualitative study outlined in this paper.

Ethical approval:

The qualitative research study outlined in this paper was approved by the Local Research Ethics Committee based at City Hospital NHS Trust, Dudley Road, Birmingham B18 7QH, UK.

\section{References}

1 Staniszewska S, West E. Meeting the patient partnership agenda: the challenge for health care workers. Int J Qual Health Care 2004; 16(1): 3-4.

2 Goddard M, Smith P. Equity of access to health care services: theory and evidence from the UK. Social Sci Med 2001; 53: 1149-1162.

3 Cappuccio F, Khadra A. Understanding health risks associated with ethnic groups: 1. People of African Origin. Pulse Clin 2001; 8: 52-53.

4 Laing A. Meeting patient expectations: healthcare professionals and service re-engineering. Health Services Manage Res 2002; 15: 165-172.

5 Department of Health. Eye Care Services Steering Group - First Report, London; 2004.
6 Philip KL, Backett-Milburn K, Cunningham-Burley S, Davis JB. Practising what we preach? A practical approach to bringing research, policy and practice together in relation to children and health inequalities. Health Educ Res 2003; 18(5): 568-579.

7 Racette L, Wilson MR, Zangwill LM, Weinreb RN, Sample PA. Primary open-angle glaucoma in Blacks: a review. Surv Ophthalmol 2003; 48(3): 295-313.

8 Chen PP. Blindness in patients with treated open-angle glaucoma. Ophthalmology 2003; 110(4): 726-733.

9 Hattenhauer MG, Johnson DH, Ing HH, Herman DC, Hodge DO, Yawn BP et al. The probability of blindness from open-angle glaucoma. Ophthalmology 1998; 105: 2099-2104.

10 Fraser S, Bunce C, Wormald R, Brunner E. Deprivation and late presentation of glaucoma: case-control study. BMJ 2001; 322: 639-643, 17 March.

11 Wormald R, Basuri E, Wright L, Evans J. The African Caribbean eye survey: risk factors for glaucoma in a sample of African Caribbean people living in London. Eye 1994; 8(3): 315-320.

12 Hennis A, Leske C. The Barbados Eye Studies: paper presented to Council at the Caribbean Health Research Council 45th Meeting 2000. West Indian J Med 2001; 50: 65-69, Supplement 2.

13 AGIS Investigators The Advanced Glaucoma Intervention Study (AGIS) 1. Baseline characteristics of black and white patients. Ophthalmology 1998; 105: 1137-1145.

14 Rahmani B, Tielsch JM, Katz J. The cause-specific prevalence of visual impairment in an urban population: the Baltimore Eye Survey. Ophthalmology 1996; 103: 1721-1726.

15 Quigley H. Number of people worldwide with glaucoma. Br J Ophthalmol 1996; 80: 389.

16 Wilson R. Racial disparities in vision impairment and blindness: causes and future research direction (editorial). Ophthalmology 2001; 108(10): 1719-1720.

17 Tielsch J, Sommer A, Katz J, Royall R, Quigley H, Javitt J. Racial variations in the prevalence of primary open-angle glaucoma: The Baltimore Eye Survey. JAMA 1991; 266: 369-374.

18 Sommer A. Glaucoma screening: too little, too late? J Gen Intern Med 1990; 5: S33-S37, (September/October Supplement).

19 Vernon SA, Ghosh G. Do locally agreed guidelines for optometrists concerning the referral of glaucoma suspects influence referral practice? Eye 2001; 15(Part 4): 458-463, August.

20 Harper R, Reeves B, Smith G. Observer variability in optic disc assessment: implications for glaucoma shared care. Ophthal Physiol Optics 2000; 20: 265-273.

21 Henson DB, Spencer AF, Harper R, Cadman EJ. Community refinement of glaucoma referrals. Eye 2003; 17(1): 21-26.

22 Vernon SA. Shared Care in Glaucoma, Glaucoma Forum, Spring 2000 issue 5, International Glaucoma Association: London.

23 Smith R. Preparing for partnership. BMJ 2003; 326.

24 Daloz L. Effective Teaching and Mentoring: Realizing the Transformational Power of Adult Learning Experiences. Jossey-Bass Publishers: San Francisco, 1986.

25 Bhopal R. Is research into ethnicity and health racist, unsound or important science? BMJ 1997; 314: 1751-1756.

26 Khaliq W, Gross M, Thyagarajan B, Jones-Webb R. What motivates minorities to take part in research? Minnesota Med 2003; 86(10): 39-42. 
27 McLean CA, Campbell CM. Locating research informants in a multi-ethnic community: ethnic identities, social networks and recruitment methods. Ethnicity Health 2003; 8(1): 41-61.

28 Landers JA, Goldberg I, Graham SL. Factors affecting awareness and knowledge of glaucoma among patients presenting to an urban emergency department. Clin Exp Ophthalmol 2002; 30: 104-109.

29 Green J, Siddall H, Murdoch I. Learning to live with glaucoma: a qualitative study of diagnosis and the impact of sight loss. Social Sci Med 2002; 55: 257-267.

30 Cross V, Shah P, Bativala R, Spurgeon P. Glaucoma Awareness and the Primary Eye-Care Service: perceptions of a sample of African-Caribbeans in Birmingham. School of Public Policy, Health Services Management Centre, University of Birmingham, 2004.
31 Hall MA, Dugan E, Zheng B, Mishra WK. Trust in physicians and medical institutions: what is it, can it be measured, and does it matter? Millbank Quart 2001; 79(4): 613-639.

32 Donoghue M. People who don't use eye services: 'Making the invisible visible'. Community Eye Health 1999; 12(31): 36-37.

33 Kreuter MW, Lukwago SN, Bucholtz DC, Clark EM, Sanders-Thompson V. Achieving cultural appropriateness in health promotion programs: targeted and tailored approaches. Health Educ Behav 2003; 30(2): 133-146.

34 Jenkins R. Ethnicity etcetera. Social anthropological points of view. In: Bulmer M, Solomos J (eds) Ethnic and Racial Studies Today. Routledge: London and New York, Introduction, 1999.

35 Beckford R. Jesus is Dread: Black Theology and Black Culture in Britain. Longman and Todd Limited: London, Darton, 1998. 